\title{
ANÁLISE DE CRESCIMENTO NA CULTURA DA BATATA SUBMETIDA A DIFERENTES LÂMINAS DE IRRIGAÇÃO'
}

\author{
ANTENOR DE OLIVEIRA AGUIAR NETTO², JOÃO DOMINGOS RODRIGUES ${ }^{3}$ e SHEILA ZAMBELO DE PINHO
}

\begin{abstract}
RESUMO - Conduziu-se um experimento na Fazenda São Manoel, localizada em São Manuel, SP, pertencente à Faculdade de Ciências Agronômicas da Universidade Estadual Paulista, com o objetivo de avaliar os efeitos de diferentes lâminas de irrigação no crescimento da cultura da batata (Solanum tuberosum ssp. tuberosum), cultivar Aracy. O ensaio foi instalado em um Latossolo Vermelho-Escuro, textura arenosa, sob uma cobertura de plástico. $\mathrm{O}$ delineamento experimental utilizado foi o de blocos ao acaso, com cinco tratamentos, cinco coletas de plantas para fins de análise de crescimento, e quatro repetições. Os tratamentos consistiam em irrigar a batata quando a tensão da água no solo atingia 15, 35, 55,75 e $1.500 \mathrm{kPa}$. O aumento nas lâminas de irrigação induz incremento no índice de área foliar, na duração da área foliar, na taxa de crescimento relativo e na taxa assimilatória líquida.
\end{abstract}

Termos para indexação: índice de área foliar, taxa de crescimento relativo, taxa assimilatória líquida.

\section{GROWTH ANALYSIS IN THE POTATO CROP UNDER DIFFERENT IRRIGATION LEVELS}

\begin{abstract}
An experiment was carried out at Fazenda São Manoel, pertaining to the Faculdade de Ciências Agronômicas of the Universidade Estadual Paulista, São Manuel, SP, Brazil, to evaluate irrigation levels in the potato (Solanum tuberosum ssp. tuberosum) growth, cv. Aracy. This work was installed in a sandy Dark-Red Latosol, under a plastic cover. The experimental design was an entirely randomized block composed by irrigation in the potato plots when the soil water potential has reached $15,35,55,75$ and $1,500 \mathrm{kPa}$, and five plant sampling time with four replicates. It was found that higher irrigation levels led to increase of the leaf area index, leaf area duration, relative growth rate and net assimilation rate.
\end{abstract}

Index terms: leaf area index, relative growth rate, net assimilation rate.

\section{INTRODUÇÃO}

Poucas são as culturas que vêm desempenhando papel tão importante como fonte de alimento para as populações, em termos de quantidade produzida e consumida, como a batata. No Estado de São Paulo, essa espécie vegetal é cultivada durante o ano inteiro, sob regime de irrigação intensivo ou suplementar.

\footnotetext{
${ }^{1}$ Aceito para publicação em 28 de junho de 1999. Extraído da tese do primeiro autor, apresentada à UNESP/FCA.

${ }^{2}$ Eng. Agrôn., Dr., Rua M, 55, Cond. Côte d'Azur, Ed. Narbonne, 201, Luzia, CEP 49045-050 Aracaju, SE. E-mail: aguiar@infonet.com.br

${ }^{3}$ Eng. Agrôn., Dr., UNESP/IB, CEP 18600-000 Botucatu, SP. E-mail: rodrigues@laser.com.br
}

Não obstante, o manejo adequado da irrigação tem sido negligenciado pelos produtores rurais, resultando em prejuízos no crescimento vegetal e conseqüentes decréscimos na produtividade e qualidade do produto para o mercado consumidor.

Dar \& Rosario (1981), investigando respostas da cultura da batata ao estresse hídrico, observaram diminuição na taxa de crescimento da cultura. Os efeitos de seis níveis de irrigação no crescimento e produtividade de duas cultivares da cultura da batata foram examinados por Wolfe et al. (1983); encontraram redução na acumulação de fitomassa e na duração da área foliar, que apresentou elevada correlação com a matéria seca total final, mas não detectaram diferenças significativas na partição de assimilados.

Hang \& Miller (1986), investigando as respostas fisiológicas da cultura da batata ao estresse hídrico, 
observaram redução no tamanho das plantas, no número de folhas, na taxa de crescimento da cultura, na taxa de crescimento do tubérculo e acréscimo na partição de assimilados.

O presente trabalho objetivou estudar as respostas da cultura da batata, cultivar Aracy, a diferentes lâminas de irrigação, através da análise de crescimento.

\section{MATERIAL E MÉTODOS}

O experimento foi realizado na Fazenda Experimental São Manoel, pertencente à Faculdade de Ciências Agronômicas, da Universidade Estadual Paulista, localizada em São Manuel, Estado de São Paulo, que apresenta as seguintes coordenadas geográficas: $25^{\circ} 51^{\prime}$ de latitude sul e $48^{\circ} 34^{\prime}$ de longitude oeste, com altitude média de $740 \mathrm{~m}$

O clima do município de São Manuel, de acordo com classificação climática de Köppen, é temperado chuvoso, constantemente úmido e com verão quente (Cfa). A temperatura média anual é de $21^{\circ} \mathrm{C}$, sendo o total médio de precipitação anual de $1.445 \mathrm{~mm}$.

O ensaio foi instalado em um Latossolo Vermelho-Escuro distrófico a moderado, textura média fase floresta tropical subcaducifólia relevo suave ondulado, cujas características físicas e químicas podem ser vistas na Tabela 1

TABELA 1. Resultados das análises físicas e químicas do solo.

\begin{tabular}{lcc}
\hline Características & \multicolumn{2}{c}{ Profundidade $(\mathrm{m})$} \\
\cline { 2 - 3 } & $0-0,2$ & $0,2-0,4$ \\
\hline Granulometria $(\%)$ & 83 & 81 \\
$\quad$ Areia & 3 & 2 \\
Silte & 14 & 17 \\
Argila & 1,53 & 1,65 \\
Densidade do solo $\left(\mathrm{kg} / \mathrm{dm}^{3}\right)$ & 2,5 & 2,5 \\
Densidade de partículas $\left(\mathrm{kg} / \mathrm{dm}^{3}\right)$ & 4,9 & 4,7 \\
$\mathrm{pH}\left(\mathrm{CaCl}_{2}\right)$ & 14 & 14 \\
$\mathrm{MO}\left(\mathrm{g} / \mathrm{dm}^{3}\right)$ & 12 & 9 \\
$\mathrm{P}\left(\mathrm{mg} / \mathrm{dm}^{3}\right)$ & 21 & 24 \\
$\mathrm{H}^{+} \mathrm{Al}$ & $\left(\mathrm{mmol}_{\mathrm{c}} / \mathrm{dm}{ }^{3}\right)$ & 1,0 \\
$\mathrm{~K}\left(\mathrm{mmol} / \mathrm{dm}^{3}\right)$ & 14 & 13 \\
$\mathrm{Ca}{ }^{2+}\left(\mathrm{mmol}_{\mathrm{c}} / \mathrm{dm}^{3}\right)$ & 5,0 & 5,0 \\
$\mathrm{Mg}^{2+}\left(\mathrm{mmol}_{\mathrm{c}} / \mathrm{dm}^{3}\right)$ & 20 & 19 \\
Soma de bases $(\mathrm{S})$ & 41 & 42 \\
Soma total de bases $(\mathrm{T})$ & 48 & 44 \\
Saturação de bases $(\%)$ & &
\end{tabular}

A capacidade de campo (CC) e a curva de retenção da água no solo foram determinadas in loco, em uma área de $2,25 \mathrm{~m}^{2}$, próximo ao local do experimento, nas camadas de $0-0,1,0,1-0,2,0,2-0,3$ e $0,3-0,4 \mathrm{~m}$ de profundidade. Considerou-se o valor médio de $0,2226 \mathrm{~m}^{3} / \mathrm{m}^{3}$ representativo da camada de $0-0,4 \mathrm{~m}$, como o teor de água no solo $(\theta)$ na CC, para fins de cálculo da lâmina líquida de irrigação.

Foram ajustados os valores obtidos experimentalmente da curva de retenção ao modelo de Genuchten, pelo método da minimização dos quadrados dos desvios (Genuchten, 1980). Com o auxílio do programa computacional Curvaret, desenvolvido por Dourado Neto et al. (1990), obteve-se a seguinte equação, com coeficiente de ajuste de 0,998:

$\theta=0,167+\frac{0,233}{\left[1+\left(1,442 \psi_{\mathrm{m}}\right)^{1,950}\right]^{0,323}}$, onde $\theta$ expressa o teor de água $\left(\mathrm{m}^{3} / \mathrm{m}^{3}\right)$, e $\psi_{\mathrm{m}}$, a tensão de água no solo $(\mathrm{kPa})$.

Utilizou-se o delineamento experimental de blocos ao acaso com parcelas subdivididas, com cinco tratamentos (parcelas), cinco épocas de coleta (subparcelas) e quatro repetições, perfazendo um total de 20 parcelas. Cada parcela experimental possuía uma área de 2,40 x 8,05 m, composta por três fileiras de plantas de batata cultivar Aracy. A área útil da parcela foi constituída pela fileira central, com um total de 16 plantas úteis, sendo 10 plantas destinadas para fins de análise de crescimento.

Os tratamentos consistiam em cinco lâminas de irrigação, aplicadas quando a tensão da água no solo atingia o valor máximo estabelecido para cada tratamento (Tabela 2), suficientes para elevar o teor de água no solo até a capacidade de campo $\left(\psi_{\mathrm{m}}=-6,7 \mathrm{kPa}\right)$. O controle de $\psi_{\mathrm{m}}$ foi realizado por meio de tensiômetros de mercúrio, instalados entre as plantas da linha central de cada parcela, nas profundidades de 0,15 e 0,30 m (Ekanayake, 1994).

TABELA 2. Caracterização dos tratamentos de irrigação na cultura da batata, cultivar Aracy.

\begin{tabular}{lccc}
\hline Tratamento & $\begin{array}{c}\text { Tensão da } \\
\text { água no solo } \\
(\mathrm{kPa})\end{array}$ & $\begin{array}{c}\text { Lâmina de } \\
\text { irrigação } \\
(\mathrm{mm})\end{array}$ & $\begin{array}{c}\text { Número de } \\
\text { irrigações }\end{array}$ \\
\hline T1 & 15 & 221,14 & 30 \\
$\mathrm{~T} 2$ & 35 & 204,40 & 15 \\
$\mathrm{~T} 3$ & 55 & 180,48 & 11 \\
$\mathrm{~T} 4$ & 75 & 132,24 & 7 \\
T5 & 1.500 & 97,82 & 3 \\
\hline
\end{tabular}


Para a tensão da água no solo de $1.500 \mathrm{kPa}$, o controle foi realizado por meio de amostragens de terra, profundidade de 0 a $0,3 \mathrm{~m}$, e determinação de $\theta$ pelo método da estufa. Para o controle do volume de água aplicado em cada parcela, foi instalado na extremidade das mangueiras um tubo de PVC, em forma de "tê", perfurado na ponta, com diâmetro externo de $12,70 \mathrm{~mm}$. No tubo foi acoplado um registro de esfera metálica de $12,70 \mathrm{~mm}$, uma luva de redução de 19,05 x 12,70 mm e um hidrômetro magnético LaoClarias CL 3005, com as seguintes características: vazão nominal de $0,0004167 \mathrm{~m}^{3} / \mathrm{s}$, diâmetro nominal de $20 \mathrm{~mm}$ e erro máximo relativo de $\pm 2 \%$.

Com o intuito de proteger a área experimental de precipitações pluviais e controlar o volume de água aplicado em cada parcela, foi construída uma estufa de plástico transparente, nas dimensões de 10,00 x 44,00 m. O plantio foi realizado no dia 12 de junho de 1995, com a cultivar Aracy, adotando-se o espaçamento de $0,35 \mathrm{~m}$ entre os tubérculos e $0,80 \mathrm{~m}$ entre as linhas. Antes do início da diferenciação dos tratamentos, realizada aos 30 dias após o plantio (DAP), foram efetuadas irrigações em toda a área experimental, com intervalos periódicos de dois dias, aplicando um total de 40,0 mm, com a finalidade de uniformizar o teor de água no solo, próximo à capacidade de campo. Esse procedimento possibilitou a brotação e o estabelecimento da cultura da batata.

Foram efetuadas cinco coletas de plantas, para determinar medidas biométricas que expressam a produtividade vegetal, aos 31, 44, 57, 70 e 84 DAP. Em cada amostragem, foram coletadas duas plantas de batata por parcela. As

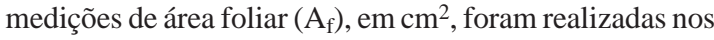
mesmos dias das coletas de plantas, utilizando-se o integrador ótico Hayasshi Denkoh AAM-8. O índice de área foliar (L), transformado para $\mathrm{m}^{2} / \mathrm{m}^{2}$, foi calculado a partir da $\mathrm{A}_{\mathrm{f}}$, média das duas plantas amostradas por parcela, e do número de plantas por $m^{2}\left(N_{p}\right): L=A_{f} \times N_{p}$.

Determinou-se a matéria seca dos tubérculos $\left(\mathrm{W}_{\mathrm{b}}\right)$, dos caules $\left(\mathrm{W}_{\mathrm{c}}\right)$ e das folhas $\left(\mathrm{W}_{\mathrm{f}}\right)$, média de duas plantas coletadas por parcela, através de secagem até massa constante em estufa com circulação forçada de ar a $70 \pm 5^{\circ} \mathrm{C}$, sendo posteriormente determinada gravimetricamente. A matéria seca total $\left(\mathrm{W}_{\mathrm{t}}\right)$ foi considerada como sendo a soma de $W_{b}, W_{c}$ e $W_{f}$. Depois, os valores de matéria seca foram transformados para $\mathrm{kg} / \mathrm{m}^{2}$.

Os valores primários de $\mathrm{W}_{\mathrm{t}}, \mathrm{L}$ e $\mathrm{W}_{\mathrm{f}}$ foram ajustados pelo método dos quadrados mínimos em relação ao tempo $(\mathrm{DAP} \rightarrow \mathrm{t}$ ), pelo método funcional (Radford, 1967), segundo o modelo exponencial cúbico, através do progra- ma ANACRES (Portes \& Castro Júnior, 1991), sendo calculados a duração da área foliar $\left(\mathrm{D}_{\mathrm{a}}\right)$, pela integral de $\mathrm{L}$ em razão do tempo, a taxa de crescimento relativo $\left(\mathrm{R}_{\mathrm{w}}=\frac{1}{\mathrm{~W}_{\mathrm{t}}} \times \frac{\mathrm{dW}}{\mathrm{dt}}\right)$, e a taxa assimilatória líquida $\left(\mathrm{E}_{\mathrm{a}}=\frac{1}{\mathrm{~L}} \times \frac{\mathrm{dW}}{\mathrm{dt}}\right)$.

\section{RESULTADOS E DISCUSSÃO}

\section{Índice de área foliar}

As equações exponenciais cúbicas ajustadas aos dados originais do índice de área foliar (L), com seus respectivos coeficientes de determinação, bem como as curvas e os valores médios observados, podem ser vistos na Fig. 1. Constata-se que na primeira coleta não há distinção entre os tratamentos, uma vez que a diferenciação das lâminas de irrigação iniciou-se aos 30 DAP. A partir da segunda coleta, verifica-se diferenciação entre os tratamentos, que progride significativamente ao longo do ciclo da cultura da batata.

Considerando o L como um índice da eficiência funcional das partes produtivas de um vegetal (Hunt, 1982), pode-se inferir que o estresse hídrico afetou significativamente essa eficiência na cultura

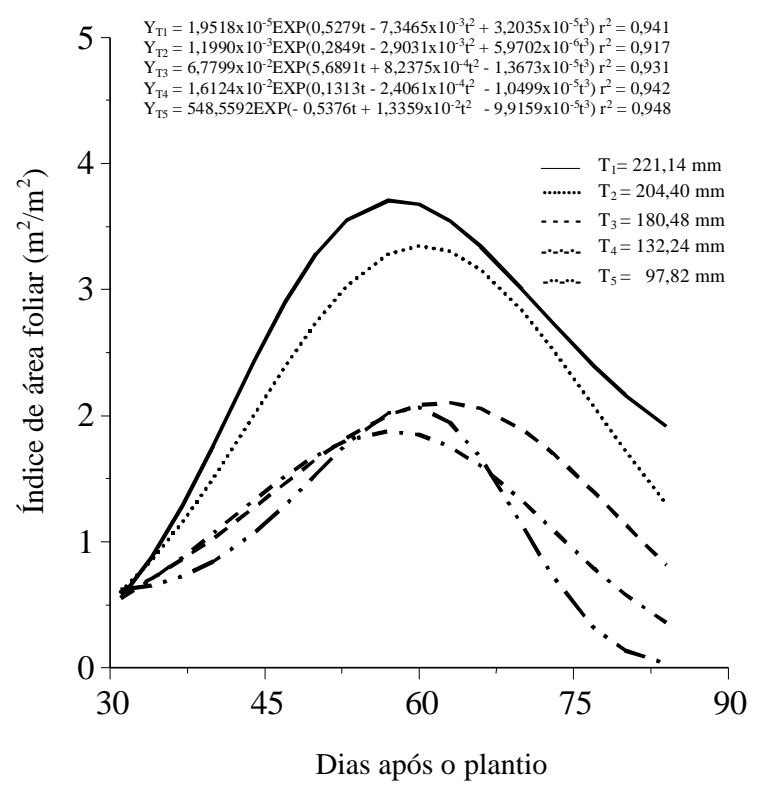

FIG. 1. Índice de área foliar, durante o ciclo de desenvolvimento da batata, cultivar Aracy, sob diferentes lâminas de irrigação $\left(T_{1}, T_{2}\right.$, $\mathbf{T}_{3}, \mathbf{T}_{4}$ e $\mathbf{T}_{5}$ ).

Pesq. agropec. bras., Brasília, v.35, n.5, p.901-907, maio 2000 
da batata. Tal resultado concorda com os relatos de Gandar \& Tanner (1976), Scaloppi \& Ferraz (1978), Dar \& Rosario (1981), Kleinkopf (1982), Wolfe et al. (1983), Hang \& Miller (1986), Duarte (1989) e Wright \& Stark (1990).

O comportamento de $\mathrm{L}$ em relação ao tempo apresenta-se semelhante em todos os tratamentos, com aumento à medida que a cultura se desenvolve, explorando o máximo espaço disponível por volta dos 60 DAP, para depois decrescer, atingindo valores próximos a zero no tratamento T5.

Os máximos valores atingidos por L nos tratamentos T1 e T2, próximos a quatro, assemelham-se aos relatados por Kleinkopf (1982) e Wright \& Stark (1990), na cultura da batata em seu estágio de desenvolvimento vegetativo. A redução de $\mathrm{L}$ no final do período estudado justifica-se pela senescência e abscisão foliar, que se intensifica nos tratamentos menos irrigados.

As relações entre o estresse hídrico e o desenvolvimento dos vegetais são muito complexas, pelo elevado número de processos fisiológicos envolvidos, que são afetados de modos e intensidades diferentes. Entretanto, sabe-se que o estresse hídrico atua direta e fisicamente, reduzindo o crescimento das plantas pela diminuição da turgescência celular (Hsiao, 1973) e exercendo um efeito negativo principalmente na fase inicial da expansão celular (Krudev, 1994). Com isso, há intensa redução da taxa de crescimento da área foliar, que se constitui num dos primeiros sintomas do estresse hídrico (Begg \& Turner, 1976).

\section{Duração da área foliar}

A Fig. 2 traz os resultados de duração da área foliar $\left(\mathrm{D}_{\mathrm{a}}\right)$, nos tratamentos ao longo do período estudado. Observa-se que a partir da diferenciação das lâminas de irrigação os tratamentos começaram a divergir, sendo os maiores valores registrados no $\mathrm{T} 1$, seguido por T2 e T3, enquanto T4 e T5 foram semelhantes aos menores valores.

Tendo em vista que a $\mathrm{D}_{\mathrm{a}}$ é a integral das curvas de L em função do tempo, é coerente que os resultados e os comportamentos dos mesmos sejam semelhantes em relação ao efeito do estresse hídrico, o que confirma que a redução da taxa de crescimento da área foliar constitui-se numa estratégia de defesa dos vegetais (Mansfield \& Davies, 1985). Contudo, essa adaptação na cultura da batata acarreta decréscimos na acumulação de matéria seca, como também relataram Dar \& Rosario (1981).

O termo duração tem provocado equívocos, porque reflete uma idéia de tempo, conflitando quase sempre com o ciclo das espécies vegetais. Porém, $\mathrm{D}_{\mathrm{a}}$ expressa em termos quantitativos quanto tempo a planta mantém sua superfície assimilatória ativa (Sesták et al., 1971).

Assim, neste trabalho preserva-se a unidade completa de $\mathrm{D}_{\mathrm{a}}\left(\mathrm{m}^{2} / \mathrm{m}^{2} /\right.$ dia $)$, para enfatizar que, apesar de ser um índice, ela representa o tamanho relativo do aparelho fotossintético que permanece na planta em relação ao tempo.

\section{Taxa de crescimento relativo}

As curvas da taxa de crescimento relativo $\left(\mathrm{R}_{\mathrm{w}}\right)$ em razão dos DAP da cultura da batata, e submetidas a diferentes lâminas de irrigação, são mostradas na Fig. 3. Observa-se que os tratamentos T1 e T2

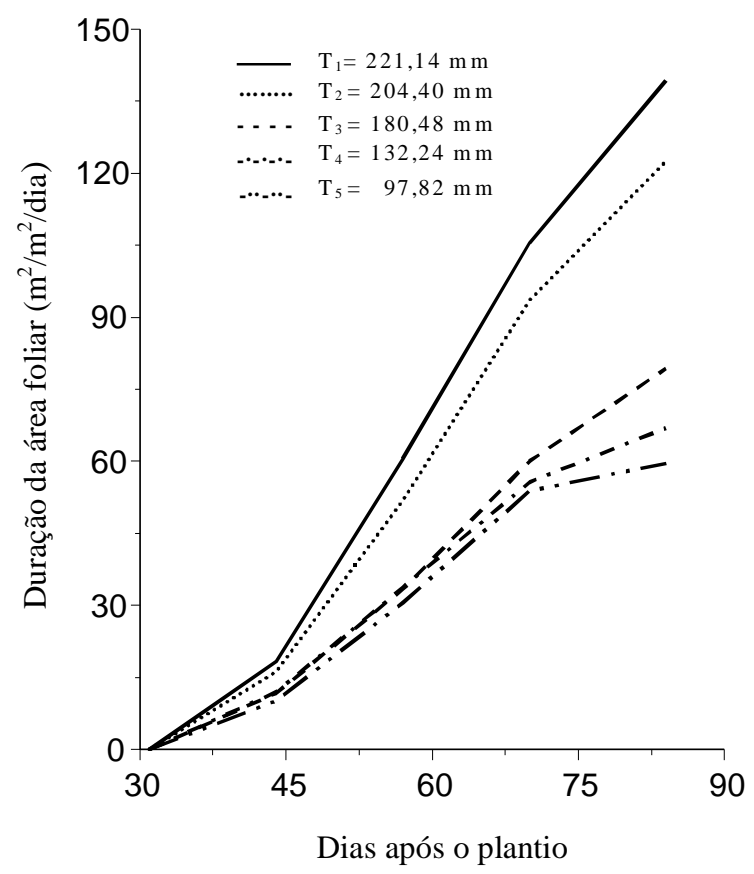

FIG. 2. Duração da área foliar durante o ciclo de desenvolvimento vegetativo da batata, cultivar Aracy, sob diferentes lâminas de irrigação $\left(T_{1}, T_{2}, T_{3}, T_{4}\right.$ e $\left.T_{5}\right)$. 
apresentaram valores semelhantes ao longo de todo o período estudado, sendo superiores aos tratamentos T3, T4 e T5.

Desde que $\mathrm{R}_{\mathrm{w}}$ foi conceituado como um índice de eficiência, já que representa a capacidade da planta em produzir material novo, pode-se deduzir que o aumento das lâminas de irrigação influencia positivamente essa variável. Além disso, Radford (1967) e Chiariello et al. (1991) argumentam que esse índice fisiológico é o mais apropriado para comparar efeitos de diferentes manejos agronômicos, por ser relativo e não depender de pressuposições matemáticas.

Fundamentalmente, o aumento de L e da razão de área foliar $\left(\mathrm{A}_{\mathrm{f}}\right)$ com as lâminas de irrigação explicam os maiores valores de $\mathrm{R}_{\mathrm{w}}$ nos tratamentos $\mathrm{T} 1$ e $\mathrm{T} 2$. Além disso, o fechamento dos estômatos em resposta ao estresse hídrico (Hsiao, 1973) também pode afetar essa variável, como observou, em Phaseolus vulgaris, Moreira (1993).

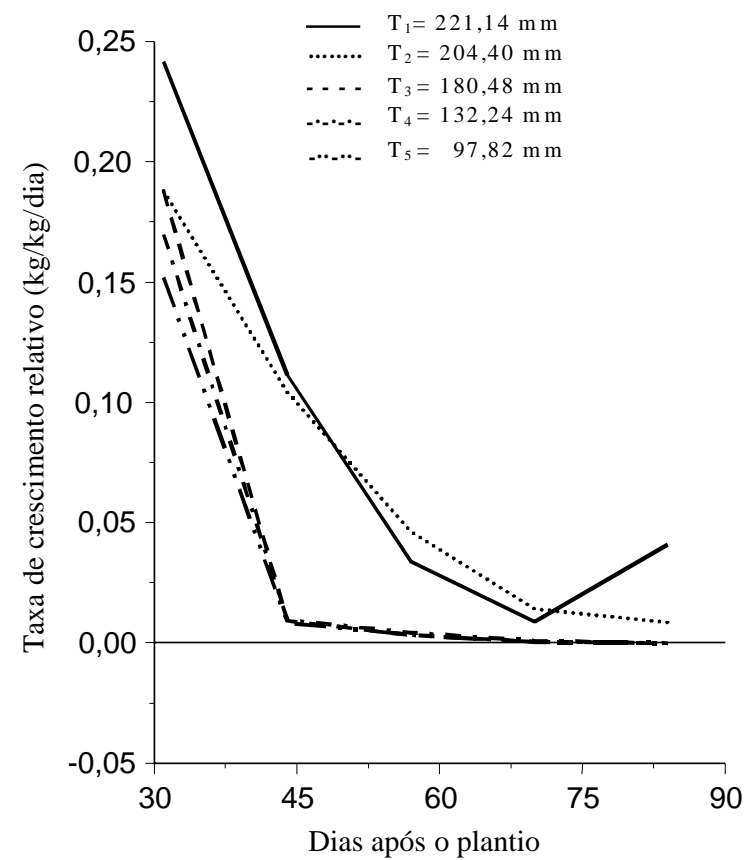

FIG.3. Taxa de crescimento relativo durante o ciclo de desenvolvimento vegetativo da batata, cultivar Aracy, sob diferentes lâminas de irrigação $\left(T_{1}, T_{2}, T_{3}, T_{4}\right.$ e $\left.T_{5}\right)$.
Em relação ao tempo, verifica-se que a tendência geral de $\mathrm{R}_{\mathrm{w}}$ é a redução com o desenvolvimento do ciclo da cultura da batata. Assim, percebe-se uma fase inicial de rápido acúmulo de material, seguida de uma com menor incremento, com um posterior período de valores próximos a zero, nos tratamentos submetidos a menores lâminas de irrigação. Somente o tratamento T1 apresenta um leve acréscimo no final do período estudado, reforçando a hipótese de um aumento de eficiência no acúmulo de material, justamente quando há translocação de fotoassimilados para os tubérculos. Esse comportamento de $\mathrm{R}_{\mathrm{w}}$ é amplamente reportado na literatura, como em Benincasa (1988), Rodrigues (1990) e Moreira (1993).

Considerando que os cálculos dos índices fisiológicos foram realizados pelo método funcional, obtendo-se valores instantâneos, verifica-se que $\mathrm{R}_{\mathrm{w}}$ se constitui no produto da $\mathrm{E}_{\mathrm{a}} \times \mathrm{A}_{\mathrm{f}}$ (Radford, 1967; Benincasa, 1988), sendo, portanto, mais fortemente influenciada pelo padrão de $\mathrm{E}_{\mathrm{a}}$.

\section{Taxa assimilatória líquida}

Os resultados referentes à taxa assimilatória líquida $\left(E_{a}\right)$ encontram-se expostos na Fig. 4. Pela análise, constata-se que o comportamento dos tratamentos T1 e T2 são semelhantes, com valores superiores aos demais. $\mathrm{O}$ tratamento T5 mostra os menores valores de $\mathrm{E}_{\mathrm{a}}$, em todo o período amostrado, apresentando inclusive dados negativos na quinta coleta.

Tendo em vista que $\mathrm{E}_{\mathrm{a}}$ expressa o balanço entre a fotossíntese e a respiração (Watson, 1952), e por ser planta $\mathrm{C}_{3}$ deve-se levar em conta também as perdas por fotorespiração, verifica-se que o estresse hídrico prejudica a assimilação de $\mathrm{CO}_{2}$ pelas folhas, o que reforça a argumentação de que a cultura da batata é bastante sensível ao estresse hídrico (Singh, 1969; Ekanayake, 1994). Nessa condição reduz a taxa de fotossíntese por unidade de área foliar (Loon, 1981), em contraposição às afirmações de Krudev (1994), de que por influência do estresse hídrico o tamanho consideravelmente reduzido das folhas pode ser compensado por uma atividade mais intensa desse órgão vegetal. Porém, os resultados dos tratamentos T1 e T2, submetidos a maiores lâminas de irrigação, discordam dos relatados na literatura, que sempre demonstram que $E_{a}$ decresce no final do ciclo 


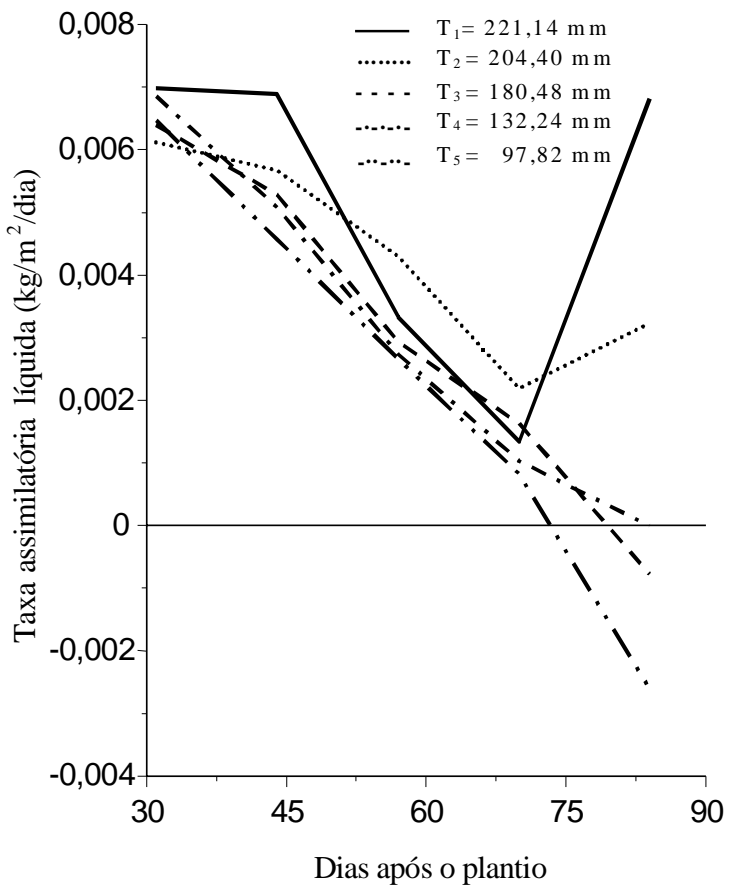

FIG. 4. Taxa assimilatória líquida durante o ciclo de desenvolvimento vegetativo da batata, cultivar Aracy, sob diferentes lâminas de irrigação $\left(T_{1}, T_{2}, T_{3}, T_{4}\right.$ e $\left.T_{5}\right)$.

das espécies vegetais, em razão da senescência foliar, como verificaram Rodrigues (1990), Urchei (1992) e Moreira (1993).

Tal fato pode ser justificado pelas variações intraespecíficas desse índice fisiológico (Watson, 1952), bem como pelo uso de diferentes modelos matemáticos para relacionar $\mathrm{L}$ e $\mathrm{W}_{\mathrm{t}}$ com o tempo, gerando comportamento variado em $\mathrm{E}_{\mathrm{a}}$, como demonstrou Calbo et al. (1989). Vale ressaltar, contudo, que a cultura da batata apresenta comportamento biológico diferente do das outras espécies vegetais relatadas pelos autores acima citados, pois ela acumula reservas nos tubérculos, e não na parte aérea. Assim, esse padrão, acrescido da senescência e fenecimento foliar, sugere uma maior eficiência no final do ciclo vegetativo.

\section{CONCLUSÃO}

A redução nas lâminas de água de irrigação afeta negativamente os índices fisiológicos do crescimento na cultura da batata, cultivar Aracy.

\section{REFERÊNCIAS}

BEGG, J.E.; TURNER, N.C. Crop water deficits. Advances in Agronomy, San Diego, v.28, p.161-217, 1976.

BENINCASA, M.M.P. Análise de crescimento de plantas: noções básicas. Jaboticabal : FUNEP, 1988. $42 \mathrm{p}$.

CALBO, A.G.; SILVA,W.L.C.; TORRES, A.T. Comparação de modelos e estratégias para análise de crescimento. Revista Brasileira de Fisiologia Vegetal, Londrina, v.1, n.1, p.1-7, 1989.

CHIARIELLO, N.R.; MOONEY, H.A.; WILLIAMS, K. Growth, carbon allocation and cost of plant tissues. In: PEARCY, R.W.; EHLERINGER, J.R.; MOONEY, H.A. (Eds.). Plant physiologycal ecology: fields and instrumentation. New York : Chapman and Hall, 1991. p.328-365.

DAR, W.D.; ROSARIO, D.A. Response of white potato (Solanum tuberosum L.) to moisture stress. Philippine Agriculturist, Laguna, v.64, p.125-134, 1981.

DOURADO NETO, D.; LIER, Q.J.V.; BOTREL, T.A.; FRIZZONE, J.A. Programa para confecção da curva de retenção da água no solo utilizando o modelo de Genuchten. Engenharia Rural, Piracicaba, v.1, p.92-102, 1990.

DUARTE, S.N. Efeitos do horário e da lâmina de irrigação na cultura da batata (Solanum tuberosum L.). Piracicaba: USP-ESALQ, 1989. 148p. Dissertação de Mestrado.

EKANAYAKE, I.J. Estudios sobre el estres por sequia y necesidades de riego de la papa. Lima : Centro Internacional de la Papa, 1994. 38p. (Guía de investigación CIP, 30).

GANDAR, P.W.; TANNER, C.B. Leaf growth, tuber growth, and water potential in potatos. Crop Science, Madison, v.16, p.534-538, 1976. 
GENUCHTEN, M.T. A closed form equation for predicting the hydraulic conductivity of unsaturated soils. Soil Science Society of American. Journal, Madison, v.44, p.892-898, 1980.

HANG, A.N.; MILLER, D.E. Yield and physiological responses of potatos to deficit, high frequency sprinkler irrigation. Agronomy Journal, Madison, v.78, p.436-440, 1986.

HSIAO, T.C. Plant responses to water stress. Annual Review of Plant Physiology, Palo Alto, v.24, p.519-570, 1973.

HUNT, R. Plant growth curves: the funcional approach to plant growth analysis. London : E. Arnold, 1982. 248p.

KLEINKOPF, G.E. Potato. In: TEARE, I.D.; PEET, M.M. (Eds.). Crop water relations. New York : J. Wiley, 1982. p.287-305.

KRUDEV, T.G. Água, vida das plantas. São Paulo : Ícone, 1994. 178p.

LOON, C.D. The effect of water stress on potato growth, development and yield. American Potato Journal, Orono, v.58, p.51-69, 1981.

MANSFIELD, T.A.; DAVIES, W.J. Mechanisms for leaf control of gas exchange. BioScience, Washington, v. 35, n.3, p.158-164, 1985 .

MOREIRA, J.A.A. Efeitos da tensão da água no solo e do parcelamento da adubação nitrogenada, sobre o crescimento e a produtividade do feijão-vagem (Phaseolus vulgaris L.). Botucatu : UNESP-FCA, 1993. 100p. Tese de Doutorado.

PORTES, T.A.; CASTRO JÚNIOR, L.G. Análise de crescimento de plantas: um programa computacional auxiliar. Revista Brasileira de Fisiologia Vegetal, Brasília, v.3, p.53-56, 1991.

RADFORD, P.J. Growth analysis formulae - their use and abuse. Crop Science, Madison, v.7, n.3, p.171-175, 1967.

RODRIGUES, J.D. Influência de diferentes níveis de cálcio, sobre o desenvolvimento de plantas de estilosantes (Stylosanthes guyanensis (Aubl.) Sw. cv. Cook), em cultivo hidropônico. Botucatu : UNESP-FCA, 1990. 180p. Tese de Livre Docência.

SCALOPPI, E.J.; FERRAZ, E.C. Dependência do crescimento das plantas ao regime de umidade do solo. Anais da Escola Superior de Agricultura Luiz de Queiroz, Piracicaba, v.35, p.169-184, 1978.

SESTÁK, Z.; CATSKÝ, J.; JARVIS, P.G. Plant photosynthetic production: manual of methods. The Hague : W. Junk, 1971. 818p.

SINGH, G. A review of the soil-moisture relationship in potatoes. American Potato Journal, Orono, v.46, p.398-403, 1969.

URCHEI, M.A. Efeitos de défices hídricos, em três estádios fenológicos, da cultura da cevada (Hordeum vulgare L.). Botucatu : UNESP-FCA, 1992. 165p. Dissertação de Mestrado.

WATSON, D.J. The physiological basis of variation in yield. Advances in Agronomy, San Diego, v.4, p.101-144, 1952.

WOLFE, D.W.; FERERES, E.; VOSS, R.E. Growth and yield of two potato cultivars to various levels of applied water. Irrigation Science, Berlin, v.3, p.211-222, 1983.

WRIGHT, J.L.; STARK, J.C. Potato. In : STEWART, B.A.; NIELSEN, D.R. (Eds.). Irrigation of agricultural crops. Madison : American Society Agronomy, 1990. p.859-888. 